was significantly higher compared to patients in GCPT group - 7 (10.3\%) and 6 $(8.8 \%)$ respectively $(p=0.038$ and $p=0.049)$. Baseline $C$-peptide was elevated in patients who developed IGT after a course of GCPT ( $850 \mathrm{pmol} / /$ before GCPT, $4099 \mathrm{pmol} / \mathrm{l}$ 4-6 hours after GCPT and $1904 \mathrm{pmol} / \mathrm{l}$ after a 3-days course of GCPT) or DM (1050 pmol//, $3170 \mathrm{pmol} / \mathrm{l}$ and $1796 \mathrm{pmol} / \mathrm{l}$ before GCPT, at peak blood glucose level and after a 3 -days course of GCPT, respectively) $(p<0.05)$. $\mathrm{C}$-peptide remained normal in the absence of CMD and in IGT patients.

Baseline HOMA-IR index was elevated in patients with IGT (4.52, 17.47, 9.67 before GCPT, at peak blood glucose level and after a 3-days course of GCPT, respectively) and DM $(5.04,15.2,10.4$ respectively) $(p<0.05)$, and normal in patients without $\operatorname{CMD}(2.2,5.84$ and 4.01 respectively) and patients with impaired fasting glucose (IFG) $(2.46,7.08$ and 5.46$)$.

HOMA-islet index analysis revealed that in the absence of CMD and at earlier stages of CMDs (IFG, IGT) insulin resistance is compensated via an increase of $\beta$-cell secretory activity. In DM patients there is a trend towards decreased $\beta$-cell secretory activity, which is associated with a significant decrease of HOMA-islet index to 64,6 at peak blood glucose levels after GCPT compared to baseline level (170) $(p<0.05)$. C-peptide, HOMA-IR and HOMA-islet index levels in OGCT patients demonstrated same trend as in GCPT patients. Significant differences were observed in patients with IGT and DM before and after oral glucose tolerance test (OGTT) on C-peptide (1042 pmol// vs. $1978 \mathrm{pmol} / \mathrm{l}$ in IGT; $1306 \mathrm{pmol} / \mathrm{l}$ vs. $2286 \mathrm{pmol} / \mathrm{l}$ in DM) and HOMA-IR (4.53 vs. 9.81 in IGT; 5.6 vs. 11.27 in DM patients), whereas in patients without CMD and in patients with IFG, C-peptide before OGTT was $489 \mathrm{pmol} / \mathrm{l}$ vs. $743 \mathrm{pmol} / \mathrm{l}$, after $-1295 \mathrm{pmol} / \mathrm{l} \mathrm{vs}$. $1488 \mathrm{pmol} / \mathrm{l}$, HOMA-IR -2.59 vs. 2.88 before OGTT and 2.88 vs. 5.85 after the test in the absence of CMD and in IFG patients, respectively. A significant decrease of $\beta$-cell function was observed in DM patients, reflected by a decrease of HOMA-islet after OGTT compared to baseline (147 vs. 78.4 ).

Conclusions: GCT leads to IGT and DM in patients with increased IR both during GCPT and long-term OGCT. Long-term OGCT is associated with more CMDs compared to GCPT.

Disclosure of Interest: None declared

DOI: 10.1136/annrheumdis-2017-eular.5748

\section{AB0324 IS LOW SERUM VITAMIN D LEVEL ASSOCIATED WITH INCREASED NEUROPATHIC PAIN IN RHEUMATOID ARTHRITIS PATIENTS? A CROSS-SECTIONAL STUDY}

H. Yesil ${ }^{1}$, U. Sungur ${ }^{2}$, S. Akdeniz ${ }^{3}$, G. Gurer ${ }^{3}$, B. Yalcın ${ }^{4}$, U. Dundar ${ }^{1} .{ }^{1}$ Physical Medicine and Rehabilitation, Afyon Kocatepe University, Afyonkarahisar;

${ }^{2}$ Physical Medicine and Rehabilitation, Ege University, Faculty of Medicine, Izmir; ${ }^{3}$ Physical Medicine and Rehabilitation, Adnan Menderes University, Faculty of Medicine, Aydın; ${ }^{4}$ Afyon Kocatepe University, Afyonkarahisar, Turkey

Background: Rheumatoid arthritis (RA) is a systemic, autoimmune, progressive condition characterised by progressive synovitis with resultant joint destruction, functional disability and significant pain. Recent experimental data indicates that there may be a neuropathic component of pain perception in RA.

Objectives: The aim of this study was to examine the development of neuropathic pain (NP) in patients with RA and its relationship with vitamin $\mathrm{D}$.

Methods: We used the Leeds assessment of neuropathic symptoms and signs (LANSS) questionnaire to evaluate NP in 93 patients with RA. Clinical parameters included general demographics, and disease activity scores were evaluated. The patients also completed Short form-36 survey, and Health Assessment Questionnaire.

Results: Of all the patients who were eligible for the study, 75 were female $(80.6 \%)$. Mean serum vitamin $\mathrm{D}$ level of the participants was calculated to be $22.8 \pm 11.9 \mathrm{ng} / \mathrm{mL}$. According to the LANSS questionnaire 31 patients $(33.3 \%)$ were classified as having NP. There was a negative correlation between vitamin $D$ levels and LANSS value $(p=0.001)$. We have determined that patients with vitamin $D$ serum levels below $20 \mathrm{ng} / \mathrm{mL}$ have significantly higher NP positivity rate $(p=0.012)$, besides they have 5.8 times more risk of developing NP when compared to patients with vitamin $D$ serum levels $\geq 30 \mathrm{ng} / \mathrm{mL}$.

Conclusions: We conclude that Vitamin D deficiency is prevalent in RA patients with NP. Once it is the right diagnosis, Vitamin D deficiency treatment is relatively easy, safe, inexpensive and with satisfactory outcomes; therefore, an underlying vitamin D deficiency should be explored in the etiology of NP in patients with RA. References:

[1] Bellucci E, Terenzi R, La Paglia GM, Gentileschi S, Tripoli A, Tani C, Alunno A. One year in review 2016: pathogenesis of rheumatoid arthritis. Clin Exp Rheumatol. 2016; 34(5):793-801.

[2] Koop SM, Klooster PM, Vonkeman HE, Steunebrink LM, van de Laar MA. Neuropathic-like pain features and cross-sectional associations in rheumatoid arthritis. Arthritis Research \& Therapy.2015; 17:237.

[3] Shehab D, Jarallah KA, Abdella N, Mojiminiyi OA, Mohamedy HA. Prospective Evaluation of the Effect of Short-Term Oral Vitamin D Supplementation on Peripheral Neuropathy in Type 2 Diabetes Mellitus. Med Princ Pract. 2015; 24:250-256.

Disclosure of Interest: None declared

DOI: 10.1136/annrheumdis-2017-eular.4395

\section{AB0325 TREAT TO TARGET AND THE REAL LIFE EXPERIENCE - DATA FROM A COHORT OF RHEUMATOID ARTHRTIS PATIENTS IN SOUTH EAST ROMANIA (CONSTANTA COUNTY)}

V.C. Suta ${ }^{1,2}$, I.-T. Andronache ${ }^{1}$, M. Suta ${ }^{2} \cdot{ }^{1}$ Rheumatology Department, IInd Internal Medicine Clinic, "St. Apostol Andrei" Emergency Clinical County Hospital Constanta; ${ }^{2}$ Faculty of Medicine, "OVIDIUS" University Constanta, Constanta, Romania

Background: Treatment target in rheumatoid arthritis (RA) is remission or low disease activity. Considering that there is no quantitative "gold standard " for measuring the disease activity, monitoring and evaluation of RA patients is made through composite scores, which have an important subjective component. Moreover, the laboratory investigations used (ESR and CRP) are commonly discordant with the clinical findings

Objectives: To evaluate disease activity and establish relations between disease activity scores and their components in RA patients

Methods: We performed a transversal study which included 447 RA patients (aged 18 to 86-years-old) admitted to our Rheumatology Department between January 2014 and December 2015. Patients' evaluation was performed by the rheumatologist. All the data obtained from the medical history, clinical examination, laboratory tests and imaging studies was recorded at the same date. All patients signed a dated informed consent at the time of admission.

Results: The study included 447 patients, mean age $62.13 \pm 11.44,85 \%$ women, accounting for a female:male ratio ( $\mathrm{F}: \mathrm{M})$ of almost 6:1 (5.7:1) with an average disease duration of $10,75 \pm 8,85$ years. $48 \%$ of our patients presented with normal CRP values $(\leq 0.5 \mathrm{mg} / \mathrm{dl})$ and values of $\leq 1 \mathrm{mg} / \mathrm{dl}$ for CRP, compatible with Boolean remission, were present in $66.6 \%$ of the patients. A significant percentage of our sample population (194 patients: $43.4 \%$ ) registered normal ESR values ( $\leq 28$ $\mathrm{mm} / \mathrm{h}$ )

Remission and LDA were registered in $18.1 \%$ up to $29.8 \%$.of the patients, depanding on the score used. The lowest rate of remission and low activity is registered through the DAS28 ESR evaluation (18.1\%). The other three scores outline similar percentages for T2T group of patients: $27.1 \%$ (SDAI), $28.7 \%$ (CDAI), and $29.7 \%$ (DAS28 CRP). The LDA group is characterized in our study by a small number of swollen joints $(<1)$, medium-normal ESR values $(<30 \mathrm{~mm} / \mathrm{h})$ and CRP values $<1 \mathrm{mg} / \mathrm{dl}$ (with the exception of SDAl). Consequently, patients with low activity based on the afore mentioned scores meet remission according to Boolean definition.

Conclusions: The disease activity and implicitly the remission rate are appreciated differently depending on the scale used. The limit between remission and low disease activity is fragile, influenced mainly by the purely subjective components of the assessment instruments. The important differences between the subjective and objective components of the evaluation scales recommend the supplementation of methods used in order to emphasize the real degree of joint inflammation.

\section{References:}

[1] Jonathan Kay, Olga Morgacheva, Daniel E Furst et al. Clinical disease activity and acute phase reactant levels are discordant among patients with active rheumatoid arthritis: acute phase reactant levels contribute separately to predicting outcome at one year. Arthritis Research \& Therapy 2014, 16:R40.

[2] Tuulikki Sokka et al. Remission and Rheumatoid Arthritis. Data on Patients Receiving Usual Care in Twenty-Four Countries. ARTHRITIS \& RHEUMATISM Vol. 58, No. 9, September 2008, pp 2642-2651.

[3] Glenn Haugeberg et al. Ten years of change in clinical disease status and treatment in rheumatoid arthritis: results based on standardized monitoring of patients in an ordinary outpatient clinic in southern Norway. Arthritis Research \& Therapy (2015) 17:219.

Disclosure of Interest: None declared

DOI: 10.1136/annrheumdis-2017-eular.6920

\section{AB0326 INFLUENCE OF NONSTEROIDAL ANTI-INFLAMMATORY DRUGS ON ARTERIAL STIFFNESS IN PATIENTS WITH RHEUMATIC DISEASES}

J.N. Kim, J.-Y. Choe, S.-K. Kim, S.-H. Park, H. Lee, C.U. Lee, J.-W. Kim. Division of Rheumatology, Department of Internal Medicine, Catholic University of Daegu School of Medicine, Daegu, Korea, Republic Of

Background: The association with adverse cardiovascular (CV) events and NSAIDs has been the topic of much debate.

Objectives: The aim of the present study was to investigate the effects of continuing NSAIDs therapy on predictable parameters for CV events.

Methods: We enrolled 155 patients with variable rheumatic diseases (95 rheumatoid arthritis, 49 systemic lupus erythematosus, 3 behçet's disease, 3 gout, 5others.) who were free from established $\mathrm{CV}$ diseases and had taken cardiovascular function tests from June 2015 to June 2016. They were divided into two groups depending on whether or not to have taken NSAIDs therapy for at least 5 years: NSAIDs taking group (91 patients) vs. non NSAIDs taking group (64 patients). For evaluating heart function, transthoracic echocardiography was used. Arterial stiffness was assessed using brachial-ankle pulse wave analysis. Results: There were no significant differences in blood pressure, serum creatinine, serum hemoglobin, total cholesterol, erythrocyte sediment rate, C-reactive protein, disease duration, age, and smoking history between the groups. The NSAIDs 